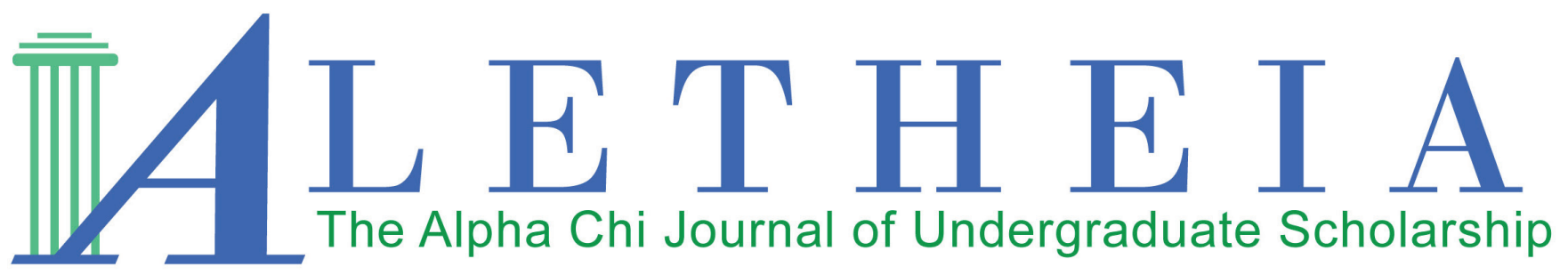

Volume 3 | Issue 1 | 2018

\title{
Service the Superior: An Examination of Women's Relationship to Justice in Ariel Dorfman's Death and the Maiden
}

\author{
Santana Batts \\ William Peace University \\ North Carolina PsiChapter
}

Vol. 3(1), 2018

Article Title: Service the Superior: An Examination of Women's Relationship to Justice in Ariel Dorfman's Death and the Maiden

DOI: $10.21081 / \mathrm{AX} 0152$

ISSN: 2381-800X

Key Words: Ariel Dorfman, feminism, revenge, justice, gender politics

This work is licensed under a Creative Commons Attribution 4.0 International License.

Author contact information is available from the Editor at editor@alphachihonor.org.

\section{Aletheia-The Alpha Chi Journal of Undergraduate Scholarship}

- This publication is an online, peer-reviewed, interdisciplinary undergraduate journal, whose mission is to promote high quality research and scholarship among undergraduates by showcasing exemplary work.

- Submissions can be in any basic or applied field of study, including the physical and life sciences, the social sciences, the humanities, education, engineering, and the arts.

- Publication in Aletheia will recognize students who excel academically and foster mentor/mentee relationships between faculty and students.

- In keeping with the strong tradition of student involvement in all levels of Alpha Chi, the journal will also provide a forum for students to become actively involved in the writing, peer review, and publication process.

- More information and instructions for authors is available under the publications tab at www.AlphaChiHonor.org. Questions to the editor may be directed to editor@alphachihonor.org.

Alpha Chi is a national college honor society that admits students from all academic disciplines, with membership limited to the top 10 percent of an institution's juniors, seniors, and graduate students. Invitation to membership comes only through an institutional chapter. A college seeking a chapter must grant baccalaureate degrees and be regionally accredited. Some 300 chapters, located in almost every state, induct approximately 11,000 members annually. Alpha Chi members have been "making scholarship effective for good" since 1922. 
Article Title: Service the Superior: An Examination of Women's Relationship to Justice in Ariel

Dorfman's Death and the Maiden

DOI: $10.21081 / \mathrm{AX} 0152$

ISSN: 2381-800X

This work is licensed under a Creative Commons Attribution 4.0 International License.

\title{
Service the Superior: An Examination of Women's Relationship to Justice in Ariel Dorfman's Death and the Maiden
}

\author{
Santana Batts \\ William Peace University \\ North Carolina PsiChapter
}

\begin{abstract}
In Ariel Dorfman's play Death and the Maiden (1991), being a woman serves to legally, politically, and socially prevent justice for Paulina, a rape and kidnapping victim who was captured by a dictatorial regime in Chile. Paulina seeks to achieve her own form of justice through extracting the truth from her alleged attacker, Roberto, while at the same time dealing with her complicated husband, Gerardo. The punishment Paulina enforces upon Roberto serves to emulate the torture she endured while captured. Gerardo's acceptance of the presidential appointment to serve as the head of the Investigating Commission on Human Rights Violations reveals that his priorities focus on climbing the professional ladder and conflict with the wellbeing of his wife, Paulina. Gerardo's assignment is to pursue cases such as Paulina's, but ultimately, he investigates only those that have led to the victims' deaths. Paulina, therefore, is tacitly deemed as undeserving of justice because her torture did not end in death. In addition to his lack of professional support, Gerardo also serves as one of Paulina's greatest oppressors through his domestic, personalized attacks and his extreme, misogynistic sense of ownership over his spouse. Gerardo essentially utilizes Paulina as a servant rather than viewing her as his equal and in doing so highlights the bias placed against women in both the public and private spheres, which demoralizes them and discredits the authenticity of their claims.
\end{abstract}

Key words: Ariel Dorfman, feminism, revenge, justice, gender politics

In Ariel Dorfman's play Death and the Maiden (1991), being a woman serves to legally, politically, and socially prevent justice for Paulina, a rape and kidnapping victim who was captured by agents of a dictatorial regime in Chile. As such, Paulina seeks to achieve her own form of justice that is designed to extract the truth from her alleged attacker, Roberto. The punishment Paulina inflicts upon Roberto serves to emulate the torture she was forced to endure while captured with the hope that her kangaroo court will force him to come clean about his sick and violent attacks against her. Meanwhile, Paulina's husband, Gerardo, not only sides with his wife's suspect but also privileges Roberto's needs as opposed to those of Paulina.
The underlying sympathy Gerardo seems to possess for his wife, at least in some instances, represents a guilty conscience concerning his past indiscretions and their effects on her state of mind, rather than actual remorse and compassion for the trauma she has undergone. Gerardo's acceptance of the presidential appointment to serve as the head of the Investigating Commission on Human Rights Violations, without even acknowledging his fragile wife's opinion, reveals that his priorities focus on climbing the professional ladder. Gerardo's assignment is to pursue cases such as Paulina's, but only to investigate those that have resulted in the victims' deaths. Paulina comments, "The members of the commission only deal with the dead, with those who 
can't speak. And I can speak" (37). Paulina, therefore, is deemed as undeserving of justice because her torture did not end in death. In addition to his lack of professional support, Gerardo also serves as one of Paulina's greatest oppressors through his use of personalized attacks and his misogynistic sense of ownership over her. Gerardo ultimately utilizes Paulina as a servant rather than viewing her as his equal and in doing so highlights the bias placed against women in both the public and private spheres, which inevitably demoralizes them and discredits the authenticity of their claims.

Paulina is portrayed as a fragile-minded, weak individual whose accounts of a particular event are seemingly less informed due to her delicate state of mind. Gender roles are overwhelmingly contested throughout this play as the foundation upon which unsubstantiated allegations rest. For example, when Roberto tells Gerardo that "She isn't the voice of civilization, you are," he overwhelmingly insults women as a gender, while simultaneously demoralizing Paulina's voice as one that does not need to be heard (49). In Kelly Oliver's Witnessing Beyond Recognition, the author uses a variety of individuals' analyses to unearth what witnessing as a victim entails, stating, "Oppression and domination succeed by undermining, damaging, or annihilating... the inner witness is necessary for the process of witnessing to support itself," something that, as a rape victim, Paulina must endure when opening up about her trauma (87). Although justice and truth have some place in the result, neither the opposition nor the defense, believe they are getting a fair trial.

Roberto's nature is unequivocally bizarre, and his tendencies seem far more convoluted than mere coincidence. As Gerardo is distressed and broken down on the side of the highway, Roberto, seeming a total stranger, decides to stop and help. Shortly after, Roberto drops Gerardo off at his house, and the new acquaintances agree to hang out in the coming days. A while later, Roberto returns to Gerardo's house and says, "So I'm listening to the radio in my car and . . . all of the sudden, it hit me. I heard your name on the news, the list of names the president's chosen for this Investigating Commission, and they say Gerardo Escobar . . . I realized who it was" (Dorfman 14). Furthermore, Roberto details that he had a sudden recollection that the spare was in his trunk and that he does not want Gerardo to have to take a taxi or tow truck the next day.
This behavior is highly suspicious and creates the impression of foul play, perhaps because Gerardo's new job would provide insight into Roberto's hidden past.

Gerardo takes Paulina for granted by treating her as his subordinate. The misogynistic complex portrayed through Gerardo's fascist-style impulsivities subject his wife to life under the oppressive rule of a dictator once again. Gerardo's domineering expectations of Paulina is emphasized early on, as the playwright has Gerardo offer up his wife's services to the unwelcomed guest. In his first appearance at the house, Gerardo tells Roberto, "we'll get together before I leave ... My wife makes a margarita that will make your hair stand on end" (Dorfman 3). Be that as it may, it is entirely possible that Paulina has something better to do than sit around and make margaritas for Gerardo's guest, but Gerardo does not hesitate to offer Paulina's services. After Roberto drops Gerardo off at the beach house he shares with Paulina, Gerardo begins to chastise Paulina for forgetting to fix the spare, saying, "Do you know what any normal man does when he gets a flat? He goes to the truck and he gets out the spare. If the spare isn't flat too, that is. If his wife happened to remember to fix the spare, right?" (citation needed). This is an insensitive remark that, within the context of the play, points the finger at Paulina, suggesting she is too dim to accomplish or remember such a task (Dorfman 4). In Gerardo's mind, she is responsible for his difficulties that night.

Gerardo uses Paulina's female status and past misfortunes as a way to discredit her desires and disregard her claims as nothing more than the inconsistent accounts of a traumatized woman. Generally, decisions that will affect both members of a domestic partnership are discussed mutually, but Gerardo does not find this to be a necessary part of their relationship. Paulina comments, "You told the president you accepted, didn't you? Before you asked me? Didn't you? I need the truth, Gerardo" (Dorfman 11). Gerardo replies, "Yes. I told him I'd do it. Yes. Before asking you" (Dorfman 11). When one half of a domestic partnership makes a substantial addition or change to their life, it is generally regarded that the other half of the partnership is at least confronted or made aware of the change. However, Gerardo sees no point in asking Paulina's opinion on their future, as if the future did not belong to the both of them. The professional opportunity at stake for Gerardo as the head of the Investigating Commission is much more enticing 
than the potential to mend his relationship, and his lack of regard for Paulina foreshadows future distrust within their relationship.

Gerardo wastes no time degrading Paulina's character and insecurities. Naturally, this tarnishes her credibility and confirms that her husband is not confident in her account of the trauma. Gerardo comments, "And my wife has . . . been a bit nervous and . . . So you'll understand that---you'll have to forgive her if she doesn't . . . And if we lower our voices a little ..." (Dorfman 13). If Gerardo cannot be a place of stability for his own wife, there is no chance of her healing. Moreover, Gerardo belittles her to Roberto, as he places sole blame on Paulina for not properly fixing their car troubles, commenting, "My wife loaned it to her mother ... you know women . . ." (Dorfman 14). Gerardo undermines women in general, which compromises the value in his character and his outlook and perspective of Paulina's rhetoric. Someone who maintains preexisting negative connotations about a person, place, or thing is likely to be biased in their judgments and expressions, so it would be unwise to conclude that Gerardo's actions and statements are without partiality. Gerardo continues to use Paulina as the butt of his jokes, commenting, "Paulina, love ... That doctor who helped me out on the road, he's staying the night ... He's a friend. So, don't be scared ... Tomorrow you can make us a nice breakfast," as if a paranoid woman would like nothing more than to wake up and cook for the stranger in her kitchen (Dorfman 18).

Roberto manages to gain entrance to the home and, without the approval of Gerardo's fragile wife, is invited to stay overnight. Quickly, Paulina welcomes the intruder and alleged torturer, into her home by binding his hands and feet, the same hostile tactics Roberto used against her during captivity. Taken aback by Paulina actions, Roberto comments, "I do not know you, madam. I have never seen you before in my life. But I can tell you this: you are extremely ill, almost prototypically schizoid" (Dorfman 32). This outburst is an external example of Roberto's first attempt to invalidate Paulina as the victim, and although Paulina clearly takes a rash and heinous approach, these actions do not serve to invalidate her but to instead illuminate the extent of her trauma. As Judith Herman states in Trauma and Recovery: "Those who attempt to describe the atrocities that they have witnessed also risk their own credibility. To speak publicly about one's knowledge of atrocities is to invite the stigma that attaches to victims" (2). By mere involvement Paulina is already being victimized because of the stigma placed upon her after her release from captivity. Conveniently, she is cited as mentally ill by both her husband and Roberto, and they both use this accusation viciously to dehumanize her.

Paulina's recognition of Dr. Miranda becomes all-consuming, and the focus rapidly shifts to the kangaroo trial she has set in place for her abuser. Paulina comments, "Good morning, Doctor . . . Miranda, isn't it? Doctor Miranda" (Dorfman 19). His appearance quickly takes precedence over everything in her life, including Gerardo. Upon walking in on the mayhem Paulina has put together, Gerardo immediately responds, "Paulina! What is this? What in the name of ... Roberto ... Doctor Miranda." (Dorfman 22). Paulina's analysis of the situation at hand is distressing to her partner, and thus controversy ensues. However, Paulina is well aware of her state of mind and counters his claims commenting: "All right then, I'm sick. But I can be sick and recognize a voice. Besides, when we lose one of our faculties, the others compensate, they get sharper, Right, Doctor Miranda?" (Dorfman 23). Definitively, this is an argument that even Gerardo does not want to participate in, despite its validity, because it has potential to jeopardize what he has accomplished within his career. Therefore, Gerardo would much rather let the situation dissipate. He does not want to recognize that although Paulina is traumatized and suffering from the consequences of her past, she could very well maintain a solid and accurate account of her trauma.

In Patricia Vieira's 2009 article "Twists of the Blindfold: Torture and Sociality in Ariel Dorfman's Death and the Maiden," the author seeks to present the inequality of the blindfold both literally and figuratively in relation to Paulina in order to address how it affects her validity and response to the situation and abuse. The article comments on the relationship between her oppressors and provides a point of view for the common ground between them. Vieira comments, "On one hand, a male bond ties him to the Doctor, with whom he discusses politics and shares sexist jokes. On the other hand, his affections for his wife interfere with the way he treats the doctor" (135). Although I do agree with Vieira in that politics and sexist jokes serve as a bonding mechanism between the two men, I would argue that Gerardo's treatment of his wife is not one of affection, but rather one of denial and guilt. Gerardo not accepting his wife's account as authentic allows him to maintain the cogni- 
tive dissonance he needs to invalidate her. And although Paulina makes it clear that Gerardo was unfaithful to some extent during her capture, it is not clear to what extent this affects their relationship. It is obvious, however, that Gerardo harbors resentment towards Paulina, and in many instances, his attitude toward her reeks of distaste and sarcasm.

According to Judith Herman's Trauma and Recovery, "The ordinary response to atrocities is to banish them from consciousness. Certain violations of the social compact are too terrible to utter aloud: this is the meaning of the word unspeakable". However, she goes a step further to explain that "Remembering and telling the truth about terrible events are prerequisites both for the restoration of the social order and for the healing of individual victims" (1). By eliminating the possibility of a witness, Paulina is left to deconstruct the situation from her recollection, which may or may not be altered from the actual occurrence, but the mere fact that she is telling and remembering these events does not suggest an altered account. The audience is never made aware that Paulina has ever accused anyone else of being her torturer besides Roberto, so it is reasonable to believe that this occurrence is triggered by the recollection of facts and painful memories. This strengthens her credibility as a witness because, although the trauma seems to have highlighted signs of PTSD, she has never before constructed a kangaroo court for any alleged attacker. Thus, this symbolizes that Paulina is confident in her actions and willing to heal in the only way she knows how.

Gerardo, however, does not see Paulina's situation this way; in fact, he does not want to see it at all. Gerardo comments, "Paulina, I want you to know that what you are doing is going to have serious consequences" (Dorfman 24). Such a comment is an obvious understatement because Paulina is well aware of what could happen to her as a result of this trial. The reality is that Gerardo is terrified of the cost this trial will weigh on his future. He remains calculated with his intentions and bitter toward Paulina all while being the man of the house because "you know women" (Dorfman 14). Well at least Gerardo believes he does. Paulina assures Gerardo that she does not intend to kill Roberto, commenting, "As he didn't kill me, I think it wouldn't be fair," but instead of simply acknowledging this rationalization, Gerardo takes his egotistical approach a step further. He says, "It's good to know that, Paulina, because you would have to kill me too, I'm warning you that if you intend to kill him, you're going to have to kill me first" (34). Although this justification may seem rash when taken at face value, it fits perfectly with Gerardo's motive to stop Paulina himself.

Essentially, Gerardo is highlighting that if Paulina kills Roberto life is no longer worth living, especially not for him, because this heinous act will put his job at risk. Gerardo's job is important to him, so much so that he found it unnecessary to inform his wife he was going to accept it despite its painful ties and the truth it denies her. His selfishness repeatedly gets in the way of Paulina's state of healing and makes her feel abandoned. Paulina was blindfolded, and therefore is automatically unfit to testify as a witness because she did not visually witness anything. Judith Herman details just how difficult it can be to not visually bear witness to one's own trauma:

"For an observer to remain clear headed and calm, to see more than a few fragments of the picture at one time, to retain all the pieces, and to fit them together. It is even more difficult to find a language that conveys fully and persuasively what one has witnessed. Those who attempt to describe the atrocities that they have witnessed also risk their own credibility. To speak publicly about one's knowledge of atrocities is to invite the stigma that attaches to the victim." (2)

Paulina's blindness to the torture means she cannot convey even to her husband the authenticity of her claims without being labeled as nothing more than a paranoid woman with severe PTSD. Moreover, Paulina is subjected to this stigma because, although she was a physical witness, she was not a visual one, and the legal act of witnessing relies solely on sight, which discredits Paulina's claims and renders her helpless in her marriage and as an oppressed victim of a failed government.

Shoshana Felmen and Dori Laub's analysis of the Holocaust within Kelly Oliver's Witnessing Beyond Recognition proclaims that "extreme subordination eliminates the conditions of possibility for subjectivity," and from "their analysis of survivors" testimonies, they deduced that the events of the concentration camps and mass murders constituted a holocaust because they "annihilated the possibly of witnesses" (89). Gerardo parallels as an oppressor at home just as Paulina's attacker does during her capture because they both serve to enslave Paulina, and by doing so, eliminate all mental, 
emotional, and personal ties with Paulina that could interfere with what is at stake: their reputations. Paulina, much like a Holocaust victim, was physically present for the atrocities against her, but, as Felmen points out, "it is impossible to testify from the inside" because "in order to reestablish subjectively and in order to demand justice, it is necessary to bear witness to the inarticulate experience of the inside," something Paulina was blinded from seeing although she was physically the subject of torture (90). Like Holocaust victims, Paulina is shut off from the outside world and forced to use her instincts to survive because she knows there will be no recognition or realization of the criminals, as they do not want to be seen.

As a blind witness, Paulina could hear, feel, smell, and touch. The truth was still emerging, the torture continuing, but she was unaware of which part of her body would be maimed next. Unfortunately, that feeling of torture and uncertainty would reside with her long after her capture. Gerardo is blind to her pain and disinterested in her revelations. Dating back to his very first conversation with Roberto about his wife, Gerardo's perspective rests on the fact that Paulina was blindfolded and everything that she has experienced after her capture is nothing more than mere paranoia. Gerardo comments, "What are you going to do with him? With him? You're going to--- what? What are you going to--- and all this because fifteen years ago someone ..." (Dorfman 34). Paulina replies, "Someone what? ... what did they do to me, Gerardo? Say it . . Y You never wanted to say it. Say it now. They ..." (Dorfman 34). Gerardo comments, "I only know what you told me that first night" (Dorfman 34). Undoubtedly, Paulina is troubled by the fact that her husband never wanted to talk about the incident after that first night, which ultimately forces Paulina to deal with the torture alone; the blindfold invalidated the event like it never happened.

Regardless of what that means for her relationship with Gerardo, Paulina is forced to face invalidation from her husband, the person from whom she desperately needs support. Gerardo comments: "Thanks to you, we may not even be able to investigate all the other crimes that--- And I'm going to have to resign" (Dorfman 36). Once again, his concern for her is virtually nonexistent, and at every turn, he forces the conversation back to himself, commenting on the way her torture, capture, and her alternative form of justice is a threat to the stability of his career. Gerardo comments, "People can die from an excessive dose of the truth," which seems to predict
Roberto's possible demise, as well as signaling that truth is not what Gerardo sees as best for the situation, perhaps because it provides the clarity Paulina needs to make difficult decisions.

Although aiding someone who has survived a severe personal trauma can be a difficult task, there is no cost in actively listening. In order to confront the situation, one must be able to define it, and in doing so, they must be able to express it and explain it to others. As quoted in Kelly Oliver's Witnessing Beyond Recognition, Felmen and Laub affirm that

The absence of an addressable other, another who can hear the anguish of one's memories and thus affirm and recognize their realness, annihilates the story. And it is, precisely, this ultimate annihilation of a narrative, that, fundamentally, cannot be heard and of a story that cannot be witnessed, which constitutes the mortal blow. (90)

All Paulina wants is to be heard, to have a voice, to have anyone listen to her story, but Gerardo will not offer this to her. He does not want to offer her this because in order to do so, Gerardo would have to confront the truth, and with that, he may actually have to redefine his role as a husband. Kelly Oliver's Witnessing Beyond Recognition details that "without a witness, I cannot exist. I am by virtue of response-ability. And truth is itself a process of emergence and reemergence between response-able subjects," and without such, one cannot move past their suffering (47).

Gerardo uses Paulina as damaged goods to be discarded or summoned whenever it is convenient for him. According to Felmen and Laub, "What ultimately matters in all processes of witnessing, spasmodic and continuous, conscious and unconscious, is not simply the information, the establishment of the facts, but the experience itself of living through testimony, of giving testimony," something she recognizes will never happen without the creation of her own trial (46). She is a woman, a service, and an inauthentic witness. Her trial is just as much against Gerardo as it is against her alleged attacker, Roberto. She is the judge, and Gerardo is literally the defense attorney, her subject, and now her inferior. She essentially puts them both on trial for their combined actions and subsequent inactions, but Gerardo sees no point in learning the truth. He comments, "Who gives a fuck what she thinks" (Dorfman 49).

As Paulina allows for both Roberto and Gerardo to prepare for the trial by giving them the information she wishes them to have, she intelligently switches parts of 
the truth about her torture in order to deliberately see if Roberto, with the help of his attorney Gerardo, will correct her mistakes, mistakes only her torturer could know. Paulina, now the enforcer of justice, confronts Roberto about his confession commenting:

I knew he would use my words for your confession. That's the sort of person he is. He always thinks he's more intelligent than everybody else . . . But I'm the one who came out on top in this game. I gave him the name Bud, Doctor ... to see if you would correct it. And you did correct it. You corrected the name Bud and you substituted the name Stud ... There were other...lies... small variations, that inserted in my story to Gerardo, and you corrected most of them. (Dorfman 65)

Despite the copious remarks from her oppressors concerning Paulina's fragile state of mind, she certainly does an excellent job of bewildering both Roberto and Gerardo in strategically inserting false claims and characters in order to receive an admission of guilt.

Despite the fact that this admission of guilt was not a legitimate confession, Roberto's unintentional corrections give Paulina the motive she needs to murder him. Paulina comments, "But I'm not going to kill you because you're guilty, Doctor, but because you haven't repented at all" (Dorfman 65). This proclamation speaks to Paulina's maturity and intent to move forward with her life. Roberto, who refuses to legitimately validate her claims subjects himself to a tragic demise, although not nearly as tragic as the behavior he has projected upon Paulina. His refusal to give in to her, and ultimately to admit his guilt, serves to represent his distaste that her inferior status now enslaves him as her subordinate.

From the time he returned to Paulina's house to recognize Gerardo as a member of the Investigative Commission, Roberto has seemingly been on a mission to mentally destroy Paulina, and therefore, he is overwhelmingly deserving of the justice she enacts upon him. There is no definitive line of good or evil for vigilante justice to cross. The reality is that, at some point, everyone crosses that line in some shape, form, or fashion. It does not have to be physical vigilantism but can also be mental. Mentally paralyzing someone can ultimately be worse than physically paralyzing them because when one breaks a bone or batters a body part, they are able to recognize the pain and act accordingly. Yet when one's mind has been shattered and manipulated, it can be difficult to recognize the problem, much less find the cure.

\section{Works Cited}

Dorfman, Ariel. Death and the Maiden. New York, NY, U.S.A., Penguin, 1992.

Herman, Judith Lewis. Trauma and Recovery. New York, NY, 1992.

Oliver, Kelly. Witnessing: Beyond Recognition. U of Minnesota, 2001.

Vieira, Patrícia. "Twists of the Blindfold: Torture and Sociality in Ariel Dorfman's Death and the Maiden." Chasqui, vol. 38, no. 2, 2009., pp. 126-37 http://ezproxy. peace.edu:2048/login?url=http://search.proquest.com/ docview/220545167?accountid=13141. 